\title{
Elevated Lactate Levels as a Predictor of Early Mortality in Patients with Severe LV Dysfunction without Shock or Hypoxemia
}

\author{
Shravan Kumar Chetti ${ }^{1}$ Sandeep Moode ${ }^{1} \quad$ Indrani Garre ${ }^{1} \quad$ Lalita Nemani $^{1}$ \\ ${ }^{1}$ Department of Cardiology, Nizam's Institue of Medical Sciences \\ Address for correspondence Shravan Kumar Chetti, Dch, DNB(DM), \\ (NIMS), Hyderabad, TS, India \\ Department of Cardiology, NIMS, Hyderabad, TS-500 082, India \\ (e-mail: shravankch@gmail.com).
}

Ind J Car Dis Wom 2019;4:68-71

\begin{abstract}
Keywords

- hypoxemia

- intensive coronary care unit

- lactate levels

- left ventricular ejection fraction

Background Hyperlactatemia in intensive coronary care unit (ICCU) admitted patients who are critically ill must be considered to be related to tissue hypoxia/ hypoperfusion. The routine measurement of lactate levels and its significance is still unclear in ICCU patients with left ventricular ejection fraction (LVEF) $<35 \%$ without hypotension and/or hypoxia.

Methods and Materials A prospective study was conducted for six months between January 2018 and June 2018 in our institute. Age $\geq 18$ years who admitted to the ICCU with LVEF less than $35 \%$ were included.

Results Total of 104 patients were included after met inclusion and exclusion criteria and consented to enrolment in the study. The most common age group involved was between 50 and 70 years (46.2\% of the patients) with a mean age of $52.5 \pm 16.3$ years. Mean lactate levels in the study population were $1.9 \mathrm{mmol} / \mathrm{L}$. Mortality was noted in five patients (4\%) in whom there were mean lactate levels of $2.58 \pm 0.37 \mathrm{mmol} / \mathrm{L}$. In the present study population, the patients with elevated lactate levels had early mortality with a $p$-value of $0.005(95 \% \mathrm{Cl}$ for difference $=0.604-1.596)$. The average duration of stay in ICCU in the study population was $3.3 \pm 1.2$ days, which was in correlation with elevated serum lactate levels. The mean $\mathrm{pH}$ of the study population was $7.2 \pm 0.19$, and mean $\mathrm{pH}$ in the mortality group was $7.06 \pm 0.21$, which was not statistically significant with those of the study population.

Conclusions From our study, patients without signs of heart failure and cardiogenic shock had increased mortality when blood lactate level was over or equal to $2.5 \mathrm{mmol} / \mathrm{L}$. So it may be used as an adjunct in identifying patients with a higher risk of mortality even without signs of heart failure, cardiogenic shock. In conclusion, according to our data, ICCU admitted patients with LVEF $<35 \%$, blood lactate is a prognostic marker for early mortality.
\end{abstract}

\section{Introduction}

Hyperlactatemia in intensive coronary care unit (ICCU) admitted patients who are critically ill must be considered to be related to tissue hypoxia/hypoperfusion. ${ }^{1}$ Even though exact cut-off values for elevated lactate levels not clearly defined, various studies used 2.0 to $2.5 \mathrm{mmol} / \mathrm{L}$ as elevated lactate level, $\geq 4.0 \mathrm{mmol} / \mathrm{L}$ as high lactate level. ${ }^{2,3}$

Over the past few years, heart failure has become a significant health problem, and the cases have been increasing every year. ${ }^{4}$ In ICCU patients admitted with heart failure, adequate tissue perfusion and the amount of compensation will determine the outcome. ${ }^{5}$ Various studies used lactate levels in risk stratification in acute coronary syndrome patients. ${ }^{6,7}$ The routine measurement of lactate levels and its significance is still unclear in ICCU patients with left ventricular
License terms

(이 (1) $\Theta \circledast$ 
ejection fraction (LVEF) $<35 \%$ without hypotension and/or hypoxia. Authors investigated whether lactate level in heart failure patients without shock and hypoxia has any correlation with early mortality.

\section{Material and Methods}

A prospective study was conducted for 6 months between January 2018 and June 2018 in our institute with the following inclusion and exclusion criteria.

Inclusion criteria: age $\geq 18$ years who admitted to the ICCU department with LVEF less than 35\%.

Exclusion criteria:

- No consent for the study.

- Hypotension (SBP $<90 \mathrm{~mm}$ and DBP $<60 \mathrm{~mm} \mathrm{Hg}$ ).

- Partial pressure of oxygen $\left(\mathrm{PO}_{2}\right)<80 \mathrm{~mm} \mathrm{Hg}$.

- Sepsis.

We included patients who were admitted to our intensive care unit with heart failure and who met the inclusion criteria. Informed consent was taken. The study population primary endpoint was taken as in-hospital mortality and patient risk factors, likely etiology of heart failure, and other comorbidities noted. All the patients were screened for sepsis, and lung pathology for hypoxia was ruled out. A detailed transthoracic echocardiogram was done with IE 33 ECHO machine (Philips), and arterial blood sample for lactate level was taken from radial artery and measured within 5 minutes with a lower detection limit of $0.1 \mathrm{mmol} / \mathrm{L}$. The number of days the patients stayed in hospital (including ICCU stay) and outcomes were noted.

\section{Results:}

The study population constituted 104 patients with a mean age of $52.5 \pm 16.3$ years. All cases met inclusion and exclusion criteria and consented to enrolment in the study. The most common age group involved was between 50 and 70 years, that is, $46.2 \%$ of the study population. Most of the study population were male patients, 73 (71.2\%) males and 31 (29.8\%) females. Males had a mean age of $52.5 \pm 17.2$ years and females had a mean age of $52.7 \pm 14.5$ years ( - Fig. 1 ).

Among the study population between both genders, various parameters like age, systolic blood pressure (SBP), diastolic blood pressure (DBP), arterial blood gas (ABG), lactate levels, hospital stay, and mortality were compared and there was no statistically significant difference in all parameters ( $\mathbf{- T a b l e ~} \mathbf{1}$ ).

The patients admitted with dilated cardiomyopathy were $68(65.4 \%)$, and with coronary artery disease were 36 (34.6\%;

-Fig. 2).

Mean lactate levels in the study population were $1.9 \mathrm{mmol} / \mathrm{L}$. Mortality was noted in five patients (4\%) in whom there were mean lactate levels of $2.58 \pm 0.37 \mathrm{mmol} / \mathrm{L}$. (-Table 2).

Table 1 Comparison of various parameters among male and female patients

\begin{tabular}{|l|l|l|l|}
\hline Variable & Male & Female & $p$-value \\
\hline Number & $73(71.2 \%)$ & $31(29.8 \%)$ & - \\
\hline Age $(\mathrm{y})$ & $52.5 \pm 17.2$ & $52.7 \pm 14.5$ & 0.937 \\
\hline $\begin{array}{l}\text { Systolic blood } \\
\text { pressure }(\mathrm{mm} \mathrm{Hg})\end{array}$ & $114.5 \pm 15.2$ & $\begin{array}{l}110.3 \pm \\
15.4\end{array}$ & 0.207 \\
\hline $\begin{array}{l}\text { Diastolic blood } \\
\text { pressure }(\mathrm{mm} \mathrm{Hg})\end{array}$ & $72.32 \pm 7.98$ & $75.34 \pm 7.4$ & 0.077 \\
\hline ABG $(\mathrm{pH})$ & $7.32 \pm 0.21$ & $7.28 \pm 0.18$ & 0.368 \\
\hline Lactate $(\mathrm{mmol} / \mathrm{L})$ & $1.59 \pm 0.81$ & $1.48 \pm 0.58$ & 0.484 \\
\hline $\begin{array}{l}\text { Hospital stay in } \\
\text { days }\end{array}$ & $4.34 \pm 2.23$ & $5.19 \pm 2.41$ & 0.099 \\
\hline Outcome-death & $4(5.4 \%)$ & $1(3.2 \%)$ & 0.586 \\
\hline
\end{tabular}

Abbreviation: ABG, arterial blood gas; $y$, years.

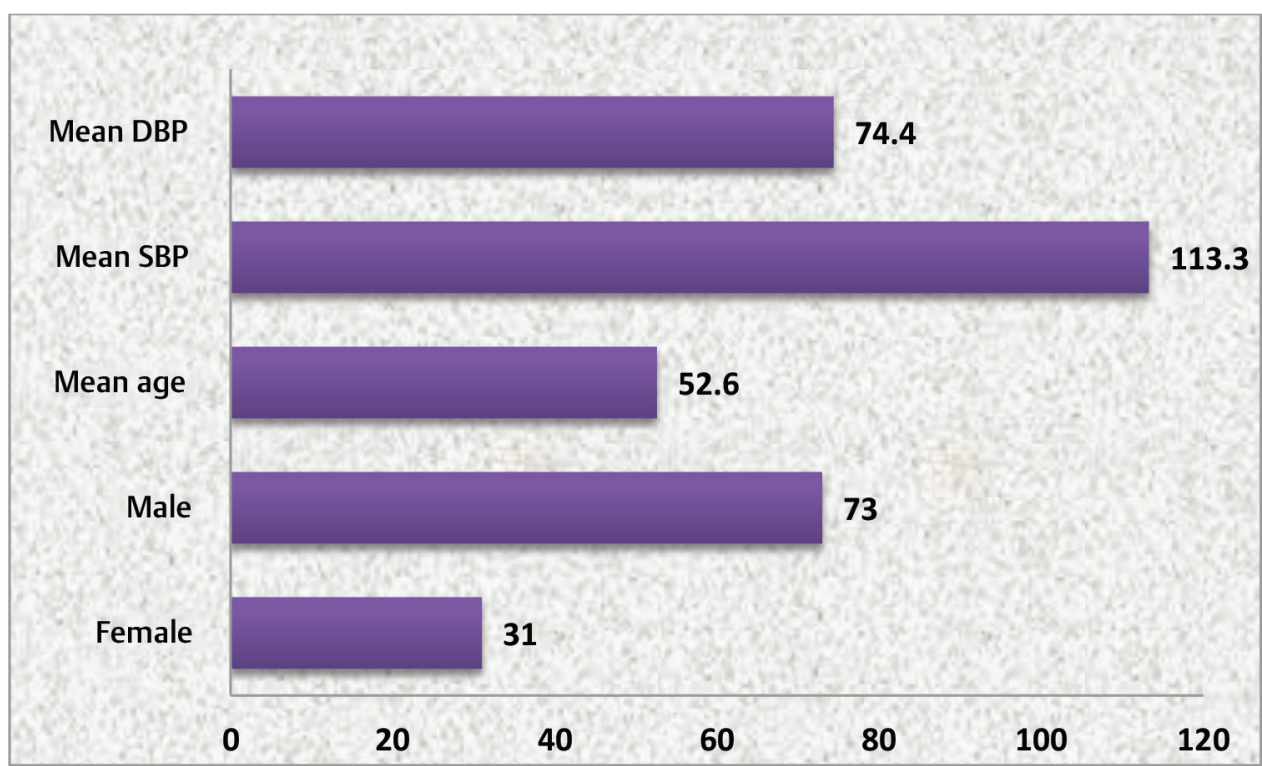

Fig. 1 Age-sex distribution, and mean blood pressure in the study population. DBP, diastolic blood pressure; SBP, systolic blood pressure. 
In the present study population, the patients with elevated lactate levels had early mortality with a $p$-value of 0.005 (95\% confidence interval $[\mathrm{CI}]$ difference $=0.604-1.596$; - Table 3).

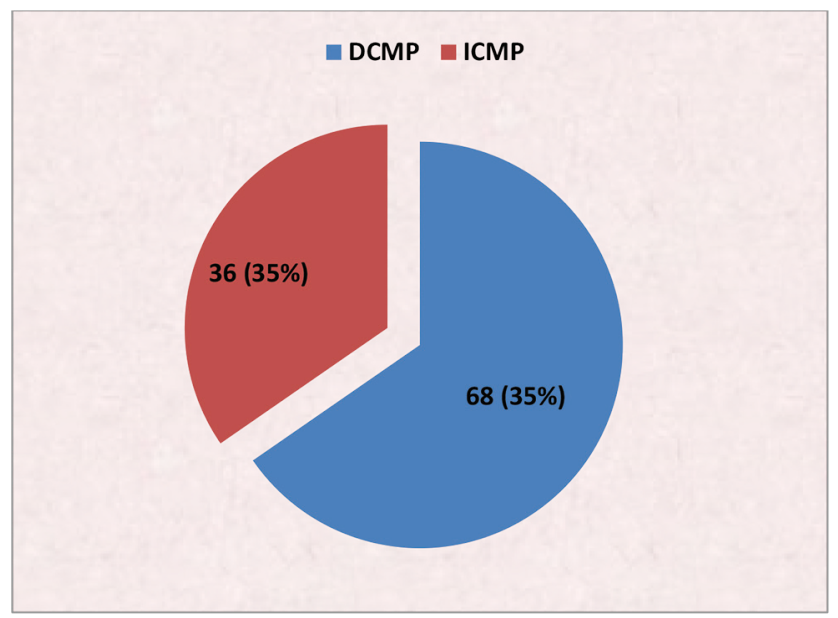

Fig. 2 Ischemic and nonischemic cardiomyopathy in study population.

Table 2 Mean lactate and $\mathrm{pH}$ in study groups

\begin{tabular}{|l|l|l|}
\hline & $\begin{array}{l}\text { Mean lactate levels } \\
(\mathrm{mmol} / \mathrm{L})\end{array}$ & $\mathrm{pH}$ value \\
\hline Death & 2.58 & 7.06 \\
\hline Discharge & 1.46 & 7.31 \\
\hline
\end{tabular}

The average duration of stay in ICCU in the study population was $3.3 \pm 1.2$ days, which was in correlation with elevated serum lactate levels.

The mean $\mathrm{pH}$ of the study population was $7.2 \pm 0.19$, and mean $\mathrm{pH}$ of death patients was $7.06 \pm 0.21$, which was not statistically significant with those of the study population (-Fig. 3).

\section{Discussion}

There was a significant relationship between elevated lactate levels and mortality in the present study population. In patients with sepsis, metabolic derangement, hypoxia, and hypoperfusion, blood lactate levels will be elevated as a response to metabolic stress and the level of elevation is used to predict early mortality, complication, and morbidity in critically ill patients.

The blood lactate levels and their clinical significance have been studied in critically ill patients admitted in ICCU. ${ }^{8}$ In heart failure patients, because of low cardiac output, end

Table 3 Two-sample T for death patients lactate vs. discharge patient lactate

\begin{tabular}{|l|l|l|l|l|}
\hline Parameter & $N$ & Mean \pm SD & SE Mean & $p$-Value \\
\hline $\begin{array}{l}\text { Death patient } \\
\text { lactate levels }\end{array}$ & 5 & $2.58 \pm 0.41$ & 0.18 & 0.005 \\
\cline { 1 - 1 } $\begin{array}{l}\text { Discharge patient } \\
\text { lactate levels }\end{array}$ & 99 & $1.46 \pm 0.61$ & 0.062 & \\
\hline
\end{tabular}

Abbreviations: SD, standard deviation; SE, standard error of the mean.

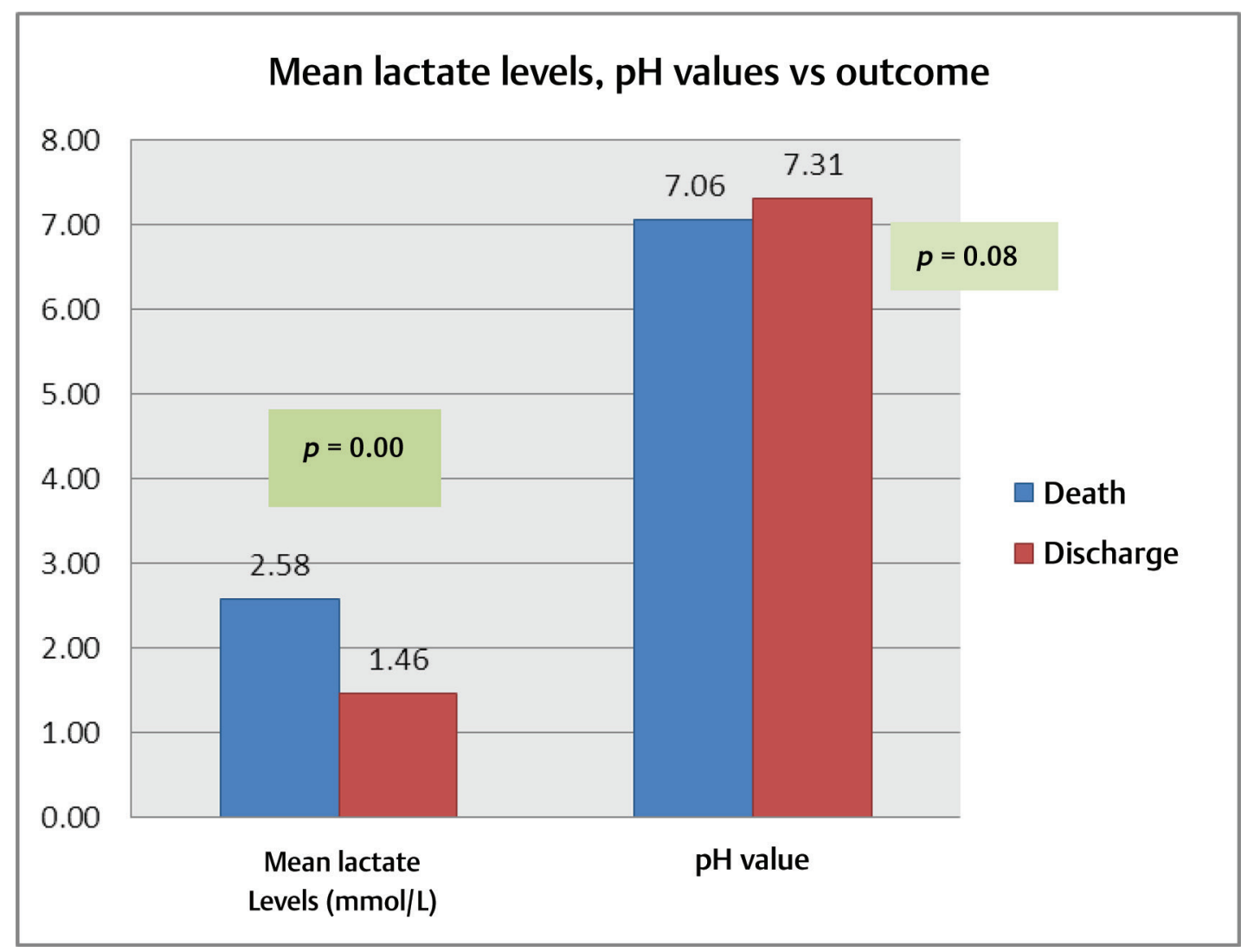

Fig. 3 Mean lactate levels and pH vs. outcome in study population. 
organ perfusion is compromised. ${ }^{9}$ Besides, due to impaired end-organ perfusion, tissue hypoxia anaerobic metabolism will occur for adenosine triphosphate (ATP) generation and lactate levels will be elevated both at the tissue level and in circulation. So measuring blood lactate levels helps to know the amount of end-organ compromise. ${ }^{10,11}$

Various biomarkers like brain natriuretic peptide (BNP) levels have been studied in heart failure patients for assessment of risk and outcome in ICCU patients. ${ }^{12}$ In acute heart failure patients, troponin level elevation was noted and used as a predictor of outcome and mortality. ${ }^{13,14}$ In this study, blood lactate levels were measured in heart failure patients who admitted in ICCU.

Our study findings were on par with a study done by Kawase ${ }^{15}$ et al, which concluded that the lactate level could be used to predict in-hospital mortality. In the present study population, patients with elevated lactate levels had early mortality.

\section{Conclusion}

Our study suggests that mortality population had a blood lactate level of over or equal to $2.5 \mathrm{mmol} / \mathrm{L}$ obtained may be used as an adjunct in identifying patients with a higher risk of mortality even without signs of heart failure and cardiogenic shock. Even the average duration of ICCU stay was higher with elevated arterial lactate levels. Besides, ABG analysis, $\mathrm{pH}$, and other comorbidities may contribute to mortality. From our study, high lactate levels in heart failure patients at ICCU admission may be used to stratify the early mortality risk.

\section{Conflicts of Interest}

None.

\section{References}

1 Andersen LW, Mackenhauer J, Roberts JC, Berg KM, Cocchi MN, Donnino MW. Etiology and therapeutic approach to elevated lactate levels. Mayo Clin Proc 2013;88(10):1127-1140

2 Howell MD, Donnino M, Clardy P, Talmor D, Shapiro NI. Occult hypoperfusion and mortality in patients with suspected infection. Intensive Care Med 2007;33(11): 1892-1899

3 Cox K, Cocchi MN, Salciccioli JD, Carney E, Howell M, Donnino MW. Prevalence and significance of lactic acidosis in diabetic ketoacidosis. J Crit Care 2012;27(2):132-137

4 Okura Y, Ramadan MM, Ohno Y, et al. Impending epidemic: future projection of heart failure in Japan to the year 2055. Circ J 2008;72(3):489-491

5 Thomas SS, Nohria A. Hemodynamic classifications of acute heart failure and their clinical application: - an update -. Circ J 2012;76(2):278-286

6 Vermeulen RP, Hoekstra M, Nijsten MW, et al. Clinical correlates of arterial lactate levels in patients with ST-segment elevation myocardial infarction at admission: a descriptive study. Crit Care 2010;14(5):R164

7 Lazzeri C, Valente S, Chiostri M, Picariello C, Gensini GF. Lactate in the acute phase of ST-elevation myocardial infarction treated with mechanical revascularization: a single-center experience. Am. J Emerg Med 2012;30(1):92-96

8 Jansen TC, van Bommel J, Bakker J. Blood lactate monitoring in critically ill patients: a systematic health technology assessment. Crit Care Med 2009;37(10):2827-2839

9 Nohria A, Lewis E, Stevenson LW. Medical management of advanced heart failure. JAMA 2002;287(5):628-640

10 Fulop M, Horowitz M, Aberman A, Jaffe ER. Lactic acidosis in pulmonary edema due to left ventricular failure. Ann Intern Med 1973;79(2):180-186

11 Gertz EW, Wisneski JA, Neese R, Bristow JD, Searle GL, Hanlon JT. Myocardial lactate metabolism: evidence of lactate release during net chemical extraction in man. Circulation 1981;63(6):1273-1279

12 Fonarow GC, Peacock WF, Phillips CO, Givertz MM, Lopatin M; ADHERE Scientific Advisory Committee and Investigators. Admission B-type natriuretic peptide levels and in-hospital mortality in acute decompensated heart failure. J Am Coll Cardiol 2007;49(19):1943-1950

13 Januzzi JL Jr. Filippatos G, Nieminen M, Gheorghiade M. Troponin elevation in patients with heart failure: on behalf of the third universal definition of myocardial infarction global task force: heart failure section. Eur Heart J2012;33(18):2265-2271

14 Fonarow GC, Peacock WF, Horwich TB, et al; ADHERE Scientific Advisory Committee and Investigators. Usefulness of B-type natriuretic peptide and cardiac troponin levels to predict in-hospital mortality from ADHERE. Am J Cardiol 2008;101(2):231-237

15 Kawase T, Toyofuku M, Higashihara T, et al. Validation of lactate level as a predictor of early mortality in acute decompensated heart failure patients who entered intensive care unit. J Cardiol 2015;65(2):164-170 